\title{
Predator-prey body size relationships of cod in a low-diversity marine system
}

\author{
Susa Niiranen ${ }^{1, *, * *}$, Alessandro Orio ${ }^{2, * *}$, Valerio Bartolino ${ }^{2}$, Ulf Bergström ${ }^{3}$, \\ Meri Kallasvuo ${ }^{4}$, Stefan Neuenfeldt ${ }^{5}$, Didzis Ustups ${ }^{6}$, Michele Casini ${ }^{2}$ \\ ${ }^{1}$ Stockholm Resilience Centre, Stockholm University, 10691 Stockholm, Sweden \\ ${ }^{2}$ Swedish University of Agricultural Sciences, Department of Aquatic Resources, Institute of Marine Research, 45330 Lysekil, Sweden \\ ${ }^{3}$ Swedish University of Agricultural Sciences, Department of Aquatic Resources, Institute of Coastal Research, \\ $\mathbf{7 4 2 4 2}$ Öregrund, Sweden \\ ${ }^{4}$ Natural Resources Institute Finland (Luke), Natural Resources, 00790 Helsinki, Finland \\ ${ }^{5}$ Technical University of Denmark, National Institute of Aquatic Resources, 2800 Kgs. Lyngby, Denmark \\ ${ }^{6}$ Institute of Food Safety, Animal Health and Environment 'BIOR', 1048 Riga, Latvia
}

\begin{abstract}
How predators select their prey largely defines ecosystem trophic structure, function and dynamics. In aquatic systems, organism body size is an important trait explaining predatorprey interactions. Here, we used a unique Atlantic cod Gadus morhua stomach content dataset with diet information from over 100000 individuals collected from the Baltic Sea in 1963-2014, to explore prey size distribution and predator-prey mass ratios in the diet of Eastern Baltic cod. Maximum and average prey sizes increased with predator size, as for cod in other systems. However, the prey size spectra found in Eastern Baltic cod stomachs reflect the low species diversity in the Baltic Sea. In general, Eastern Baltic cod feed on smaller prey in relation to their body size than other cod populations. Due to the truncated prey size distribution in the Baltic Sea, cod cannibalism functions as a compensatory mechanism that allows Baltic cod to reach their prey size potential. On the other hand, small- and intermediate-sized cod prey mainly on a few invertebrate prey species, potentially making them vulnerable to changes in these prey populations. Our results encourage further studies disentangling the relative effects of prey preference and prey availability on cod trophodynamics in species-poor systems such as the Baltic Sea.
\end{abstract}

KEY WORDS: Diet • Body size · Predator-prey mass ratio • Gadus morhua • Baltic Sea • Stomach content data

\section{INTRODUCTION}

The ever-increasing pressures on marine ecosystems make it necessary to understand how keystone, ecosystem-shaping species interact with their environment. Organism body size is an important trait defining the nature of trophic interactions in aquatic systems (Woodward \& Warren 2007). Consequently, the size ratios of predators and their prey can define

\footnotetext{
${ }^{*}$ Corresponding author: susa.niiranen@su.se
}

${ }^{* *}$ These authors contributed equally to this work trophic interaction strengths affecting, for example, predator growth and condition. In fish, a positive correlation prevails between predator body size and the maximum size of their prey (Scharf et al. 2000, Barnes et al. 2010), such that larger individuals can prey on a wider selection of prey items available than the smaller ones. The maximum predator-prey size ratio varies with fish morphology and gape size (Scharf et al. 2000). On the other hand, the average realized size

() The authors 2019. Open Access under Creative Commons by Attribution Licence. Use, distribution and reproduction are unrestricted. Authors and original publication must be credited. 
ratios are affected by both predator preference of prey and prey availability (Jennings \& Blanchard 2004), and can also be indicative of food chain length or ecosystem stability (Jennings \& Warr 2003).

Atlantic cod Gadus morhua is a central species of North Atlantic fisheries that plays a key role in shaping marine food web dynamics (Frank et al. 2007). In the Baltic Sea, a large brackish water body with relatively low species richness (Ojaveer et al. 2010), the abundance and average body size of Eastern Baltic cod (hereafter Baltic cod) have declined dramatically since the mid-1980s (ICES 2017, Orio et al. 2017), affecting both the fisheries and ecosystem functioning (Casini et al. 2008). The body condition of Baltic cod has decreased since the late 1990s, which has been related to food limitation, due to a spatial mismatch between cod and their fish prey and/or decreased availability of benthic prey, but also to increased metabolic costs caused by hypoxia, as well as increased parasite infestations (Eero et al. 2012, 2015, Casini et al. 2016). The relative importance of these different mechanisms is yet to be understood.

We used a unique cod stomach content dataset collected in the Baltic Sea in 1963-2014 (Huwer et al. 2014, ICES 2016) to study prey size in the diet of Baltic cod. We analyzed the realized maximum, minimum and mean predator-prey length ratios, together with changes in predator-prey mass ratios (PPMRs) and prey size distribution in the diet throughout cod ontogeny. Our results from the Baltic Sea are discussed in relation to findings from other North Atlantic cod populations and earlier findings from the Baltic Sea. We also discuss their relevance in the more general context of marine food web dynamics.

\section{MATERIALS AND METHODS}

The cod diet dataset was compiled in 2012-2014 and covers 107069 cod sampled by trawling in the Baltic Sea in 1963-2014, whose stomach contents were recorded to the highest taxonomic resolution (Huwer et al. 2014). All analyses in this study are based on prey abundance and individual predator and prey length measurement data found in cod stomachs sampled in the Baltic Proper (International Council for the Exploration of the Sea [ICES] subdivisions 25-28). To minimize the effect of prey degradation on the analysis of prey size, only prey items indicated as having been in good condition were included in the analysis. Prey abundance and size distribution in the field are not accounted for; hence the results are indicative of realized, not necessarily preferred, cod diet. All data are available at ICES (www.ices.dk).

A linear least-squares regression was used to estimate the relationship between mean prey and predator body length for 43606 prey items found in 15660 cod $>21 \mathrm{~cm}$ following the methods of Scharf et al. (2000). Changes in the minimum and maximum prey size with increasing predator size were analyzed using quantile regression for the $1^{\text {st }}$ and $99^{\text {th }}$ quantiles, respectively.

PPMR (i.e. weight $t_{\text {predator }} /$ weight $_{\text {prey, }}$ an index of the relative size difference between a predator and its prey) was calculated for cod $\geq 15 \mathrm{~cm}$ and their main prey species, namely sprat Sprattus sprattus, herring Clupea harengus, cod Gadus morhua and an epibenthic isopod (Saduria entomon) (Pachur \& Horbowy 2013, ICES 2016). Median PPMR and its variability were then studied across all main prey species, for fish prey only, and individually for different fish prey. Due to the limited quantity of samples with reliable individual prey weight information, predator and prey lengths were converted into body weights using known length-weight relationships for Eastern Baltic fish from FishBase (Froese \& Pauly 2009) and for $S$. entomon collected in the same area as the stomach samples. Smaller species (e.g. Mysis mixta) were not included due to sporadic length measurements and lack of well-established methods to convert length into weight. Consequently, the realized average PPMR between cod and their prey (i.e. across all prey) is likely somewhat higher than estimated in this study.

To analyze the ontogenetic changes of prey body size (length) distribution in cod diets, we produced density plots of the body sizes of the main prey items found in cod stomachs per different size groups of $\operatorname{cod}(10 \mathrm{~cm}$ size bins). Mysids were also excluded from this analysis.

\section{RESULTS AND DISCUSSION}

\subsection{Changes in prey sizes with increasing cod size}

The maximum and mean prey body sizes (measured in length) increased with cod (predator) body size, while the minimum prey body size remained nearly constant (Fig. 1). Hence, the size range of the consumed prey increased, and cod became more generalist with increasing body size. Only few prey items longer than $25 \mathrm{~cm}$, mainly smaller cod and flounder Platichthys flesus, were found in the Baltic cod stomachs. Both the slope and intercept of the maximum predator-prey body size ratio were smaller 


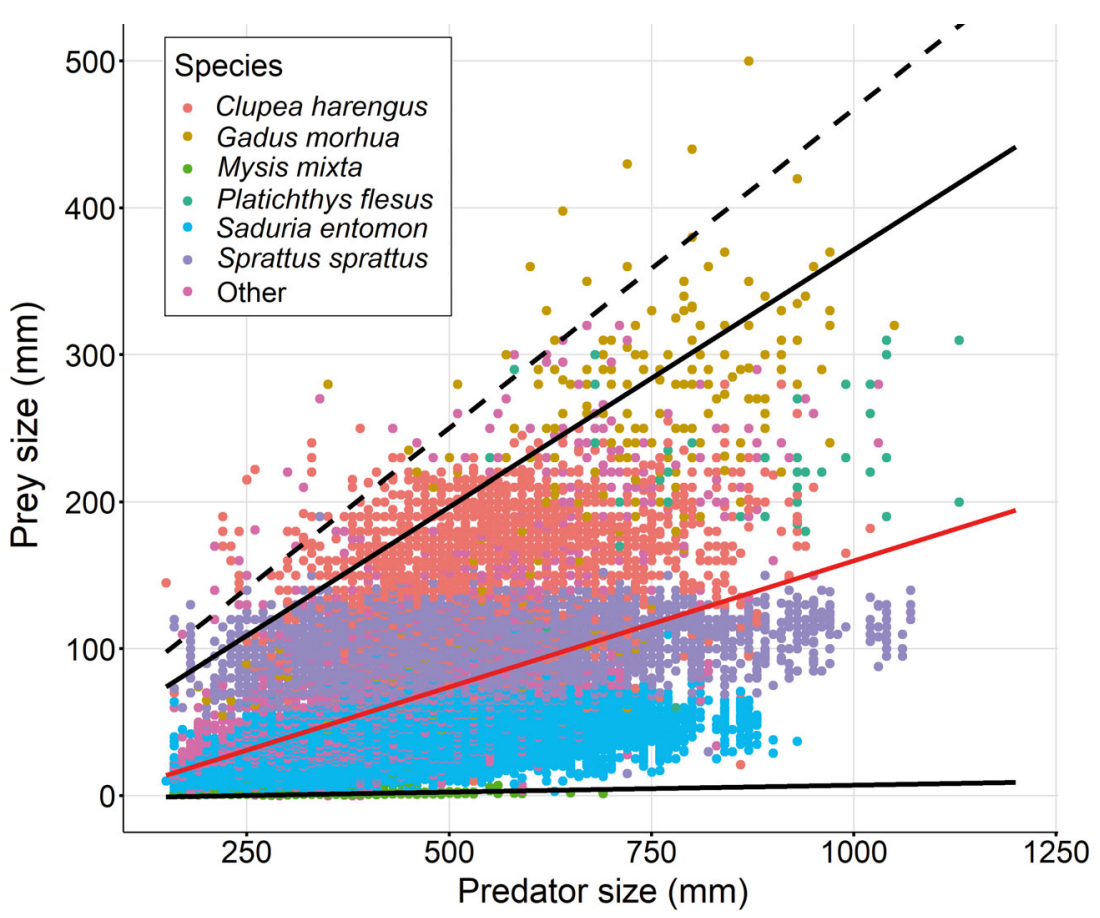

Fig. 1. Predator-prey size for Baltic Sea cod. Each point represents a prey item consumed by a cod. Regression lines represent the minimum, maximum (black solid lines) and mean (red solid line) prey sizes in relation to cod size for the Baltic Sea, and observed maximum prey size for the Northwest Atlantic (black dashed line, from Scharf et al. 2000). Regression equations are presented in Table 1

for the Baltic than the Northwest Atlantic cod (Scharf et al. 2000; Table 1, Fig. 1), implying that Baltic cod of all sizes, but particularly larger cod, are feeding on smaller prey sizes than their body size and gape would allow. The mean prey sizes eaten by large cod $(>40 \mathrm{~cm})$ were also larger in the Northwest Atlantic than in the Baltic, possibly reflecting the rather narrow prey size distribution in the Baltic Sea. It should be noted that the frequencies of small invertebrates, and other easily digested prey items, are likely underestimated in such stomach content studies (Baker et al. 2014). Further, the Baltic data do not include samples from shallow coastal areas and offshore banks, i.e. areas hosting a higher diversity of potential prey species, so we may have somewhat underestimated the total variability in Baltic cod diet.

\subsection{Predator-prey mass ratio}

Larger Baltic cod generally fed on smaller fish prey in relation to their own body mass than smaller cod (Fig. 2a), as previously observed in North Sea cod (Floeter \& Temming 2003). Average realized PPMRs between Baltic cod and their fish prey (PPMR: 250-1250 for $\operatorname{cod}>35 \mathrm{~cm}$ ) were clearly higher than between Western Baltic cod $>35 \mathrm{~cm}$ and their fish prey (PPMR 150, Ursin \& Arntz 1985). The preferred PPMR that also accounts for the available prey field between North Sea cod and their fish prey (PPMR: 10-50 in Floeter \& Temming 2003 for cod $>35 \mathrm{~cm}$ ) is also lower than the realized PPMR for Baltic cod and their fish prey. This may indicate that prey availability largely defines the realized PPMR (see also Ursin \& Arntz 1985 and Floeter \& Temming 2003), particularly as the average PPMR between Baltic cod and their fish prey closely reflects that of sprat, the most abundant prey fish species of Baltic cod (Fig. 2a; Pachur \& Horbowy 2013). However, as our analysis does not account for prey availability in the field, more focused studies on the role of prey size preference versus prey availability in defining cod diet are needed.

For small cod $(<35 \mathrm{~cm})$ the realized prey speciesspecific PPMRs for sprat and herring prey are similar. In the case of larger cod capable of eating larger prey, the sprat-specific PPMR increased with cod size, while the herring-specific PPMR remained relatively constant (Fig. 2a). The realized prey speciesspecific PPMRs for cod $<70 \mathrm{~cm}$ preying on sprat and herring are in agreement with the preferred speciesspecific PPMRs previously found in the Baltic Sea (40-400 and 30-120, respectively; Bundgaard \& Sparholt 1992). The cod-specific (i.e. cannibalism) PPMR was lower than for other prey $(>60 \mathrm{~cm}$, PPMR $=35-100$ ), and did not increase with predator weight.

Table 1. Regression equations relating maximum, mean and minimum prey size to predator size. PY: maximum, mean or minimum prey total length $(\mathrm{mm})$; PD: predator total length $(\mathrm{mm})$. Quantiles listed are those used to estimate upper and lower bounds of prey size/predator size. Values for US North Atlantic from Scharf et al. (2000)

\begin{tabular}{|c|c|c|c|c|c|}
\hline Area & Maximum & Mean & Minimum & $\mathrm{n}$ & Quantiles \\
\hline Baltic Sea & $P Y=0.350 P D+21.5$ & $P Y=0.172 P D-12.0$ & $P Y=0.009 P D-2.2$ & 43606 & $99^{\text {th }}-1^{\text {st }}$ \\
\hline Northwest Atlantic & $P Y=0.435 P D+32.6$ & $P Y=0.199 P D-21.1$ & $P Y=0.022 P D-6.7$ & 23460 & $99^{\text {th }}-1^{\text {st }}$ \\
\hline
\end{tabular}



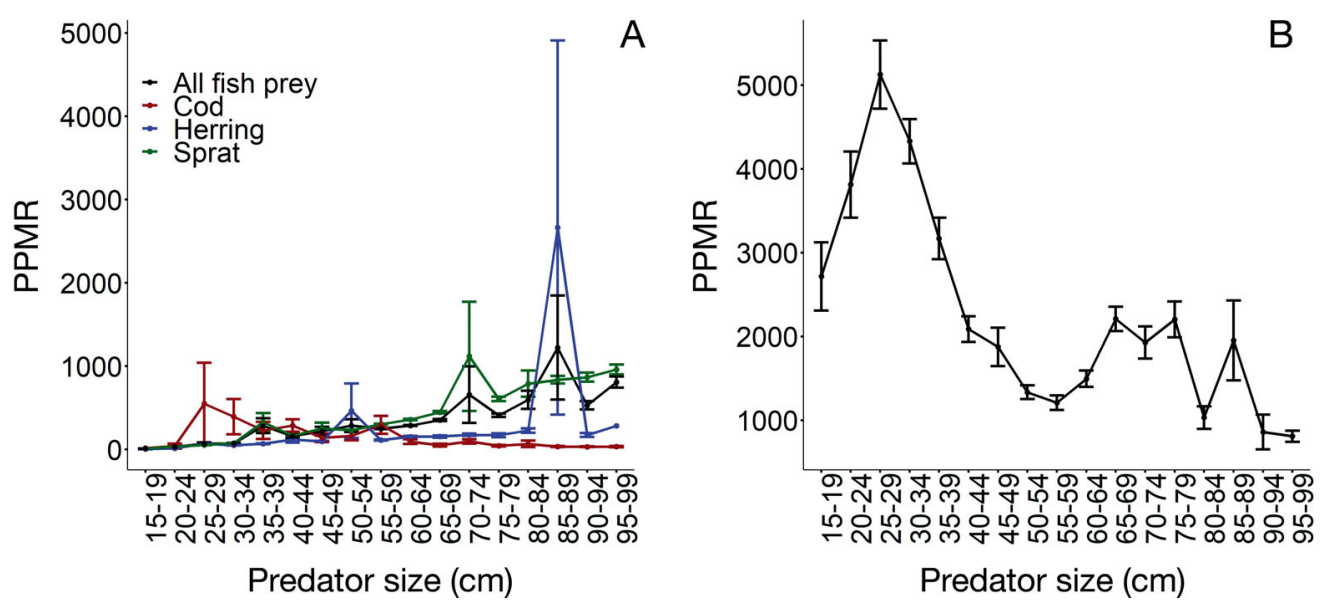

Fig. 2. Predator-prey mass ratio (PPMR) for different predator (cod) size classes in 1963-2014 including (a) only fish prey (all fish prey: herring, sprat and cod) or (b) fish prey and the isopod Saduria entomon. Error bars represent mean $\pm \mathrm{SE}$

Including Saduria entomon, a large isopod crustacean constituting a major proportion of benthic prey eaten by cod (ICES 2016), in the analysis yielded higher PPMRs (Fig. 2b). In this case, the PPMR was lower for larger and mainly piscivorous cod than for smaller, benthic-feeding cod. These PPMR values for Baltic cod are higher than those for fish predators in many other systems, where invertebrate prey have also been accounted for (e.g. Jennings \& Warr 2003, Barnes et al. 2010), even if the smallest prey have been excluded from our analysis. Our findings agree well with previous studies linking high average PPMR with short food chains and also lower food web stability (Jennings \& Warr 2003). Indeed, the relatively species-poor open Baltic Sea food web has undergone a reorganization in the past, including cod collapse and changes in the relative species composition of pelagic fish and zooplankton, driven by fishing and changes in climate (Casini et al. 2009).

\subsection{Body size distributions of ingested cod prey}

Larger cod on average preyed on larger individuals of the same species than smaller cod (Fig. 3a-d). However, in many cases, the prey size distribution also broadened with predator size, as larger cod still also preyed on smaller prey items. This can contribute to the capability of cod to be flexible in their diet. Also, the limited choice of prey items for small cod, due to their small gape size and confinement to benthic habitat (Huwer et al. 2014), is reflected in the prey size distribution curves (Fig. 3). Small cod fed mainly on small invertebrate prey, such as $S$. entomon (Fig. 3) (Huwer et al. 2014), potentially making them vulnerable to the negative effects of deep-water hypoxia on benthic fauna, which is a concern in the Baltic Sea (Carstensen et al. 2014, Casini et al. 2016). A decrease in benthic prey may also increase the vulnerability of larger cod via reduced diversification of energy flows (Brose 2010). For the intermediate-sized cod $(30-59 \mathrm{~cm})$, the observed prey size distribution curve is bimodal, such that the 2 peaks correspond to the body sizes of $S$. entomon and sprat or small-sized herring (Fig. 3e), reflecting the feeding role of cod across 2 different habitats, the benthic and the pelagic. However, they also preyed on young cod (Figs. 1 \& 3d), implying that cod cannibalism can contribute towards filling potential gaps at the lower end of the prey size distribution (see also Nellen 1986), in addition to fulfilling the feeding potential for large cod.

\section{CONCLUSIONS}

The stomach content database analyzed in this study shows that Baltic cod feed on smaller prey than other Northern Atlantic cod stocks. The large proportion of benthic prey in Baltic cod diet contributes to high overall PPMRs, but the PPMRs are also high when only accounting for main fish prey. Due to truncated prey size structure in the brackish Baltic Sea, cannibalism is one of the few mechanisms via which large Baltic cod fulfill their prey size potential. Even if cod are adaptable in their diet, relatively few prey items were found in large numbers in the stomachs of Baltic cod, likely reflecting the low species diversity in the open Baltic Sea. 

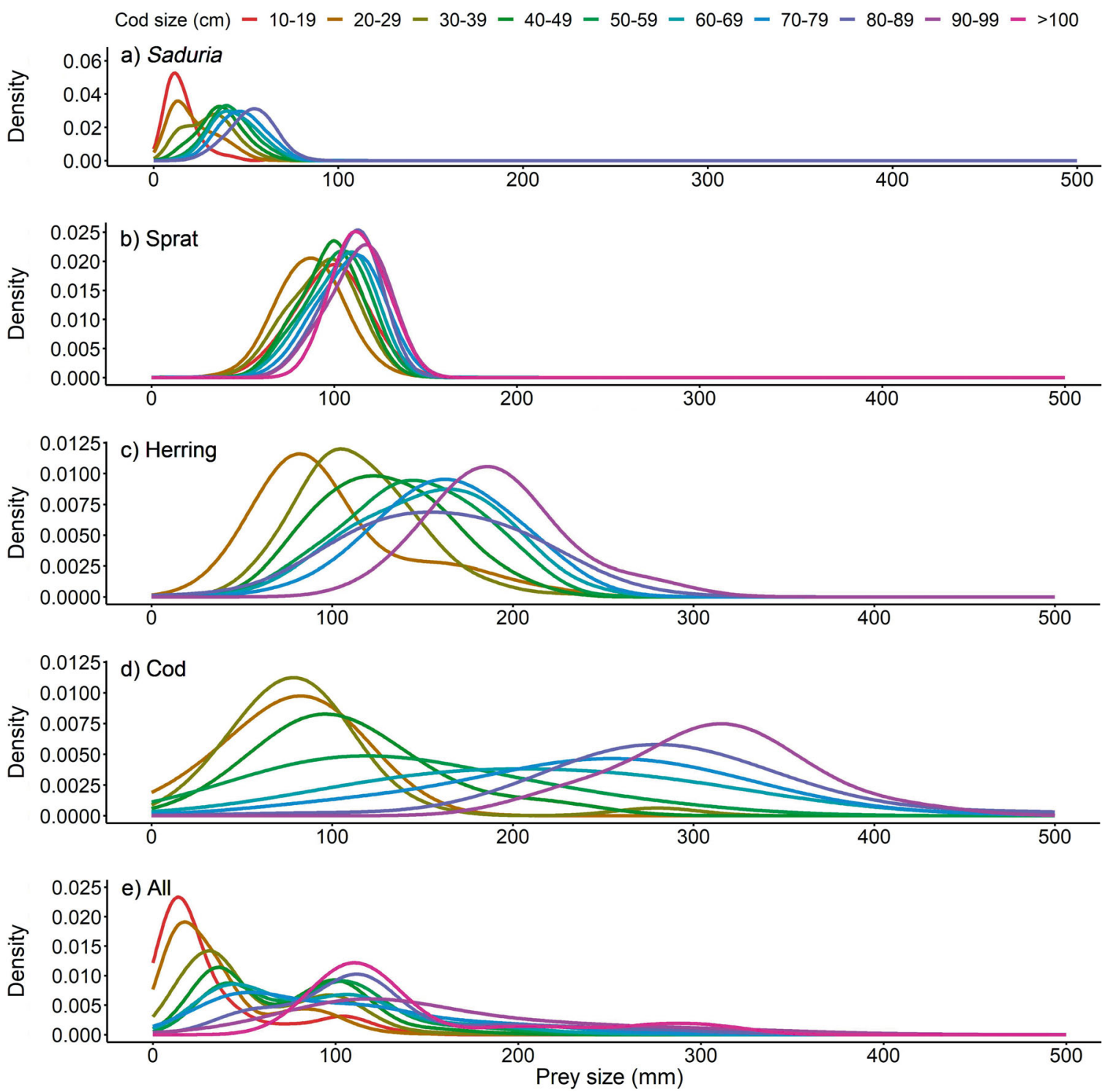

Fig. 3. Prey size distribution (in length) for different sizes of cod and their prey: (a) Saduria entomon, (b) sprat, (c) herring, (d) cod and (e) all (sprat, herring, cod, flatfish and S. entomon)

Acknowledgements. This work was done under the umbrella of the ICES Study Group on Spatial Analyses for the Baltic Sea (SGSPATIAL) and the ICES Workshop on Spatial Analyses for the Baltic Sea (WKSPATIAL and WKSPATIAL 2). The work was partially financed by the BONUS INSPIRE project supported by the Joint Baltic Sea Research and Development Programme BONUS (Art 185), funded jointly by the EU, the Swedish Research Council Formas (Sweden), Innovation Fund Denmark and Academy of Finland (Finland). V.B. was partially funded by the EU FP7 project MareFrame (G. A. no. 613571). S.N. was partially funded by the BONUS BLUEWEBS project supported by the Joint Baltic Sea Research and Development Programme BONUS (Art 185), funded jointly by the EU and the Swedish Research Council Formas. The authors acknowl- edge 3 anonymous reviewers, whose comments helped to improve the quality of this manuscript.

\section{LITERATURE CITED}

Baker R, Buckland A, Sheaves M (2014) Fish gut content analysis: robust measures of diet composition. Fish Fish 15:170-177

* Barnes C, Maxwell D, Reuman DC, Jennings S (2010) Global patterns in predator-prey size relationships reveal size dependency of trophic transfer efficiency. Ecology 91:222-232

Brose U (2010) Body-mass constraints on foraging behaviour determine population and food-web dynamics. Funct Ecol 24:28-34 
Bundgaard I, Sparholt H (1992) Length based multi-species model for estimation of predation mortalities of herring and sprat in the Baltic. ICES Document, CM/D:16. ICES, Copenhagen

Carstensen J, Andersen JH, Gustafsson BG, Conley DJ (2014) Deoxygenation of the Baltic Sea during the last century. Proc Natl Acad Sci USA 111:5628-5633

* Casini M, Lövgren J, Hjelm J, Cardinale M, Molinero JC, Kornilovs G (2008) Multi-level trophic cascades in a heavily exploited open marine ecosystem. Proc R Soc B 275:1793-1801

Casini M, Hjelm J, Molinero JC, Lövgren J and others (2009) Trophic cascades promote threshold-like shifts in pelagic marine ecosystems. Proc Natl Acad Sci USA 106:197-202

Casini M, Käll F, Hansson M, Plikshs M and others (2016) Hypoxic areas, density-dependence and food limitation drive the body condition of a heavily exploited marine fish predator. R Soc Open Sci 3:160416

Eero M, Vinther M, Haslob H, Huwer B, Casini M, StorrPoulsen M, Köster FW (2012) Spatial management of marine resources can enhance the recovery of predators and avoid local depletion of forage fish. Conserv Lett 5: 486-492

Eero M, Hjelm J, Behrens J, Buchmann K and others (2015) Eastern Baltic cod in distress: biological changes and challenges for stock assessment. ICES J Mar Sci 72:2180-2186

Floeter J, Temming A (2003) Explaining diet composition of North Sea cod (Gadus morhua): prey size preference vs. prey availability. Can J Fish Aquat Sci 60:140-150

Frank KT, Petrie B, Shackell NL (2007) The ups and downs of trophic control in continental shelf ecosystems. Trends Ecol Evol 22:236-242

Froese F, Pauly D (2009) FishBase. www.fishbase.org (accessed 11 May 2017)

Huwer B, Neuenfeldt S, Rindorf A, Andreasen H and others (2014) Study on stomach content of fish to support the assessment of good environmental status of marine food webs and the prediction of MSY after stock restoration. Final report for EU contract No MARE/2012/02. https:// www.thuenen.de/en/cross-institutional-projects/study-

Editorial responsibility: Alistair Hobday,

Hobart, Tasmania, Australia on-stomach-content-of-fish/

ICES (2016) Report of the Workshop on Spatial Analyses for the Baltic Sea (WKSPATIAL), 3-6 November 2015, Rome, Italy. ICES CM 2015/SSGIEA:13. ICES, Copenhagen

ICES (2017) Report of the Baltic Fisheries Assessment Working Group (WGBFAS), 19-26 April 2017, Copenhagen, Denmark. ICES CM 2017/ACOM:11. ICES, Copenhagen

Jennings S, Blanchard JL (2004) Fish abundance with no fishing: predictions based on macroecological theory. J Anim Ecol 73:632-642

Jennings S, Warr KJ (2003) Smaller predator-prey body size ratios in longer food chains. Proc R Soc B 270:1413-1417

Nellen W (1986) A hypothesis on the fecundity of bony fish. Meeresforschung 31:75-89

Ojaveer H, Jaanus A, MacKenzie BR, Martin G and others (2010) Status of biodiversity in the Baltic Sea. PLOS ONE 5:e12467

Orio A, Florin AB, Bergström U, Šics I, Baranova T, Casini M (2017) Modelling indices of abundance and size-based indicators of cod and flounder stocks in the Baltic Sea using newly standardized trawl survey data. ICES J Mar Sci 74:1322-1333

₹Pachur ME, Horbowy J (2013) Food composition and prey selection of cod, Gadus morhua (Actinopterygii: Gadiformes: Gadidae), in the Southern Baltic Sea. Acta Ichthyol Piscat 43:109-118

* Scharf FS, Juanes F, Rountree RA (2000) Predator size-prey size relationships of marine fish predators: interspecific variation and effects of ontogeny and body size on trophic-niche breadth. Mar Ecol Prog Ser 208:229-248

Ursin E, Arntz WE (1985) On the prey size of cod (Gadus morhua) in the western Baltic. ICES Document CM/ J:14. ICES, Copenhagen

Woodward G, Warren PH (2007) Body size and predatory interactions in freshwaters: scaling from individuals to communities. In: Hildrew AG, Raffaelli D, EdmondsBrown R (eds) Body size: the structure and function of aquatic ecosystems. Cambridge University Press, Cambridge, p 98-117

Submitted: February 25, 2019; Accepted: August 8, 2019 Proofs received from author(s): September 16, 2019 